\title{
Effects of Different Material Total Solid on Biogas Production Characteristics
}

\author{
Yu-Ming $\operatorname{Sun}^{1}$, Xiao-Mei Huang ${ }^{1, *}$, Yin-Hu Kang ${ }^{1}$ \\ ${ }^{1}$ Chongqing University, Chongqing 400045, China
}

\begin{abstract}
In China, livestock manure emission has resulted in severe pollution to the environment and it is an efficient spreading agent of diseases. For this reason, the biogas has gotten a rapid development in the past few decades. As a kind of renewable and clean energy, many studies have indicated the prospect of biogas to replace fossil fuels in the future. However, the methane industrial production process is unstable due to various factors. Therefore, it is necessary to enhance the biogas fermentation efficiency. In this paper, the influences of the raw materials and the total solids (TS) concentration on biogas production characteristics are studied, where the utilization of raw materials can be reflected by the biogas production rate in the results. The results showed the anaerobic fermentation cycle is prolonged and biogas yield increases, but the utilization decreases with TS increases.
\end{abstract}

\section{Introduction}

With the exploration of world population and the rapid development of social economy, the earth's resources and environment are under great pressure in the 21 st century [1]. Therefore, increasing interest and confidence have been paid to biomass, which is deemed as a valuable renewable energy from solar energy [2]. In China, biomass energy mainly derives from urban living garbage, forestry and timber waste, animal manure, industrial effluents, crop stalks, etc. All of them are featured with high carbon content and easy availability [3]. The development of biomass energy technique can not only reduce the ecological vicious cycle and greenhouse effect, but also substitute fossil fuels in the form of natural gas, coal, and petroleum. Thus it becomes an important pathway to relieve the energy crisis and environmental pollution [4].

As a new process converting the organic waste into usable energy, the biogas fermentation technology has received worldwide attention. In terms of technology, policy, economy and environment, Europe leads the utilization of biogas. It has the largest number of promotions, best efficiency, most mature technology of biogas anaerobic digestion in the world [5-6]. Among European countries Germany is the greatest biogas producer currently. Furthermore, Germany is transforming the raw material from livestock manure and crop straw into industrial scale production [7], such as organic crops (corn, straw, grass, etc.), municipal sewage sludge, livestock manure, industrial and food-processing enterprises waste, and urban household waste [8]. It also adopts different anaerobic digestion processes according to the engineering requirements. The United States started later until the 1970s to establish biogas facilities
[9] because of the oil crisis. Therefore, biogas projects in the United States mainly concentrate upon farms. Most are used to generate electricity. In addition, since the 70 's of the last century, Sweden has focused upon the development of biomass, proposing substituting renewable energy for fossil fuels before 2020. It has a great target to become the first country which doesn't rely on oil and coal throughout the world [10]. Besides, the raw materials of the biogas project in Sweden are mainly from the local industry, municipal wastewater and agricultural waste [11].

This paper shows that the total biogas yield increases and the anaerobic fermentation cycle prolongs but utilization efficiency of raw materials decreases with the increase in TS on the study of biogas production rate, biogas yield, production cycle and $\mathrm{CH}_{4}$ content of the anaerobic fermentation through different TS on using different materials.

\section{Materials and methods}

\subsection{Materials introduction}

Fermentation materials: The cattle manure and wheat straw as the target fermentation materials and the characteristics of cattle manure and wheat straw listed in Table 1 which measured by a Muffle Furnace and an Elemental Analyzer.

Inoculum: The fermented substrate deriving from the laboratory after anaerobic digestion with dry cattle manure as the fermenting material and remaining in a stable state.

The wheat straw is minced into small segments with scales ranging from $30 \mathrm{~mm}$ to $50 \mathrm{~mm}$ in advance. The

\footnotetext{
${ }^{*}$ Corresponding author: $\underline{\text { hxm1980@,cqu.edu.cn }}$
} 
pretreated wheat straw is used as material in a part of the experiment. The wheat straw is soaked in $8 \%$ $\mathrm{Ca}(\mathrm{OH})_{2}$ solutions for 24 hours, soaked and then washed out to neutral before.

Table 1. The characteristics of cattle manure and wheat straw.

\begin{tabular}{|c|c|c|c|c|c|c|c|c|}
\hline $\begin{array}{c}\text { Characteristi } \\
\text { cs }\end{array}$ & $\begin{array}{c}\text { TS } \\
(\%)\end{array}$ & $\begin{array}{c}\text { VS } \\
(\%)\end{array}$ & $\begin{array}{c}\text { VS/T } \\
\text { S }\end{array}$ & $\begin{array}{c}\mathrm{C} \\
(\%)\end{array}$ & $\begin{array}{c}\mathrm{N} \\
(\%)\end{array}$ & $\begin{array}{c}\mathrm{H} \\
(\%)\end{array}$ & $\begin{array}{c}\mathrm{S} \\
(\%)\end{array}$ & $\mathrm{C} / \mathrm{N}$ \\
\hline $\begin{array}{c}\text { Cattle } \\
\text { manure }\end{array}$ & $\begin{array}{c}85.0 \\
4\end{array}$ & $\begin{array}{c}72.2 \\
7\end{array}$ & 0.85 & $\begin{array}{c}31.2 \\
9\end{array}$ & $\begin{array}{c}4.5 \\
0\end{array}$ & $\begin{array}{c}1.1 \\
1\end{array}$ & $\begin{array}{c}0.2 \\
6\end{array}$ & 6.95 \\
\hline Wheat straw & $\begin{array}{c}89.0 \\
1\end{array}$ & $\begin{array}{c}74.7 \\
3\end{array}$ & 0.84 & $\begin{array}{c}41.8 \\
0\end{array}$ & $\begin{array}{c}1.0 \\
5\end{array}$ & $\begin{array}{c}1.8 \\
2\end{array}$ & $\begin{array}{c}0.8 \\
1\end{array}$ & $\begin{array}{c}39.8 \\
1\end{array}$ \\
\hline
\end{tabular}

\subsection{Experimental system of fermentation}

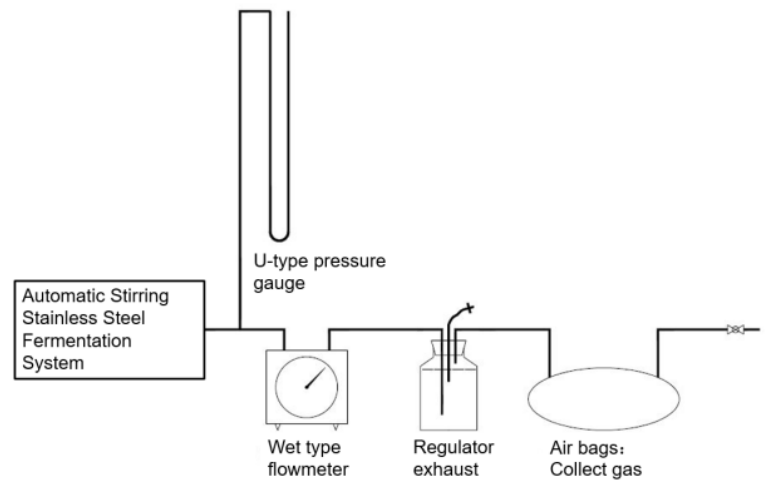

Fig. 1. Experimental system of fermentation.

The experimental system of anaerobic digestion is exhibited in Fig.1. The biogas, produced in the automatic mixing stainless steel fermentation system, passes wet flowmeter, regulator cylinder, and aluminum foil sampling bag in sequence. During the experiments, the internal pressure inside the reactor is kept constantly at $1600 \mathrm{~Pa}$.

\subsection{Operating conditions}

Six sets of experiments with different test materials and TS are involved in this paper, as Table 2 shows. The experiment mainly focuses on how Total Solid (TS) affects biogas anaerobic fermentation under different feed loads, raw materials, raw material processing and conditions as shown in Table 2.

Table 2. Operational conditions of biogas fermentation.

\begin{tabular}{|c|c|c|c|c|}
\hline $\begin{array}{c}\text { Group } \\
\mathrm{s}\end{array}$ & Materials & TS & $\begin{array}{c}\text { Temper } \\
\text { ature }\end{array}$ & $\begin{array}{c}\text { Tank } \\
\text { pressure }\end{array}$ \\
\hline I & Cattle manure & \multirow{3}{*}{$7.4 \%$} & \multirow{6}{*}{$\begin{array}{c}35^{\circ} \mathrm{C} \pm 5 \\
{ }^{\circ} \mathrm{C}\end{array}$} & \multirow{6}{*}{$1600 \mathrm{~Pa}$} \\
\hline II & $\begin{array}{c}\text { Cattle manure + } \\
\text { wheat straw }\end{array}$ & & & \\
\hline III & $\begin{array}{c}\text { Cattle manure }+ \\
\text { pretreated } \\
\text { wheat straw }\end{array}$ & & & \\
\hline IV & Cattle manure & \multirow{3}{*}{$10.0 \%$} & & \\
\hline V & $\begin{array}{c}\text { Cattle manure + } \\
\text { wheat straw }\end{array}$ & & & \\
\hline VI & $\begin{array}{c}\text { Cattle manure }+ \\
\text { pretreated } \\
\text { wheat straw }\end{array}$ & & & \\
\hline
\end{tabular}

\section{Results and discussion}

\subsection{Effect of TS on anaerobic digestion characteristics}

\subsubsection{Biogas production rate}

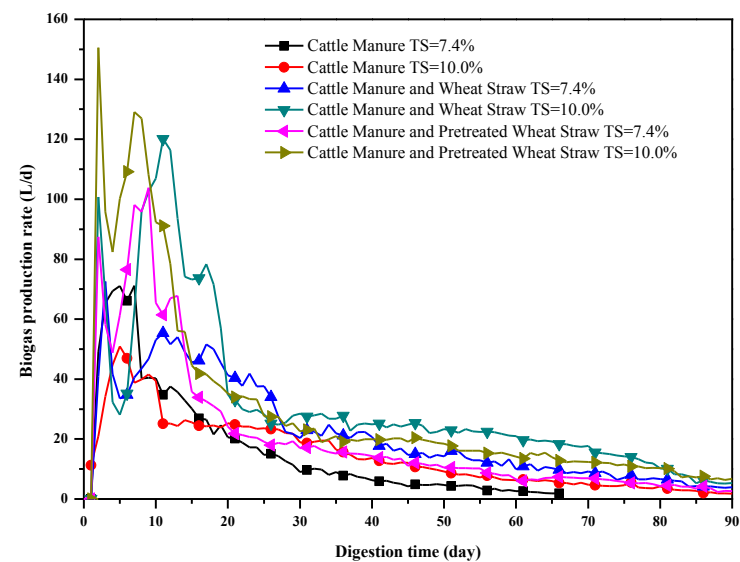

Fig. 2. Biogas production rate at different material and total Solid.

Although the raw materials and material ratios are varying, Fig. 2 reveals that the biogas production rates of the six sets of cases vary in a similar trend. The curved lines of biogas production rate reach the peak in the early days, and then the rate of daily biogas yield is damped. Compared with the line chart of the same kind of raw materials but different TS, it can be seen that the time of the peak daily biogas yield has been advanced and the daily biogas production rate has increased at $\mathrm{TS}=10.0 \%$, only one raw material in different situations.

When using cattle manure and wheat straw as the fermentation raw material, compared with $\mathrm{TS}=7.4 \%$, the biogas yield at $\mathrm{TS}=10.0 \%$ was one day ahead of time and increases by $38.7 \%$ at the first peak and by $117.2 \%$ at the second peak. In the middle and late stages of fermentation, the daily production rate at $\mathrm{TS}=10.0 \%$ is higher than that at $\mathrm{TS}=7.4 \%$. By focusing on the set of cattle manure and pretreated wheat straw, the effect of TS on the biogas production rate can be examined. Compared with $\mathrm{TS}=7.4 \%$, the daily biogas production rate at $\mathrm{TS}=10.0 \%$ is $72 \%$ higher at the first peak and $23 \%$ at the second. Furthermore, the biogas production rate reaches its peak value 2 days ahead of time. Under the same conditions, when single cattle manure is used as the fermentation raw material, the peak biogas production rate at $\mathrm{TS}=10.0 \%$ is $28.4 \%$ lower than that at $\mathrm{TS}=7.4 \%$. The reason may be that after the capping, an anaerobic environment has not been formed in whole reactor, and the non-methanogens bacterium multiply quickly with the increase of organic matter content, which makes the accumulation of organic acid and the activity of methanogens inhibit in acidic environment.

\subsubsection{Biogas yield}




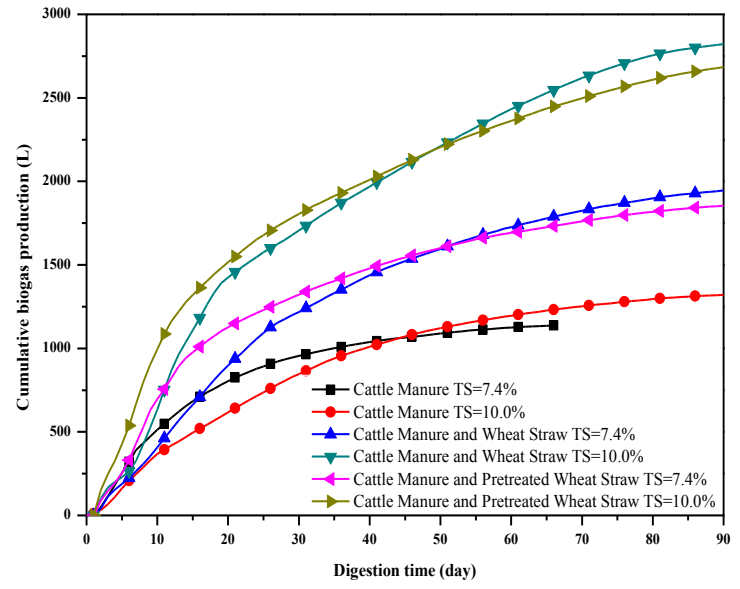

Fig. 3. The cumulative biogas production in different material and total solid.

It is observed that the total biogas production at $\mathrm{TS}=10.0 \%$ is higher than that at $\mathrm{TS}=7.4 \%$ in whole fermentation cycle.

When using single cattle manure as the raw material, in the total anaerobic fermentation cycle, it needs 12 and 38 days to achieve the cumulative biogas production of $50 \%$ and $90 \%$ at $\mathrm{TS}=7.4 \%$, but 22 and 59 days at $\mathrm{TS}=10.0 \%$. It can be seen that the biogas production cycle has a long delay at $\mathrm{TS}=10.0 \%$. Under the same conditions, when cattle manure and wheat straw are used as the raw material at $\mathrm{TS}=7.4 \%$, and reaches $50 \%$ and $90 \%$ of the total biogas production in the first 22 and 63 days. Compared with the former, the total biogas production increases by $45 \%$ over the entire reaction cycle, reaching $50 \%$ and $90 \%$ of the total biogas production on the $22 \mathrm{nd}$ and 65 th day respectively at $\mathrm{TS}=10.0 \%$. The total biogas production from cattle manure and pretreated wheat straw is $1853.36 \mathrm{~L}$ at $\mathrm{TS}=7.4 \%$. It reaches $50 \%$ and $90 \%$ of the total biogas production in the first 14 and 57 days under the same conditions, and the cumulative biogas production in the first 30 days is $71 \%$ of the total biogas production. Being different from $\mathrm{TS}=7.4 \%$, the total biogas production is $2684.54 \mathrm{~L}$ at $\mathrm{TS}=10.0 \%$, although the biogas yield has increased, the time to reach $50 \%$ and $90 \%$ of total is delayed by 2 and 7 days, the cumulative biogas production in the first 30 days is $67 \%$ of the total biogas production.

\subsection{3 $\mathrm{CH}_{4}$ percentage}

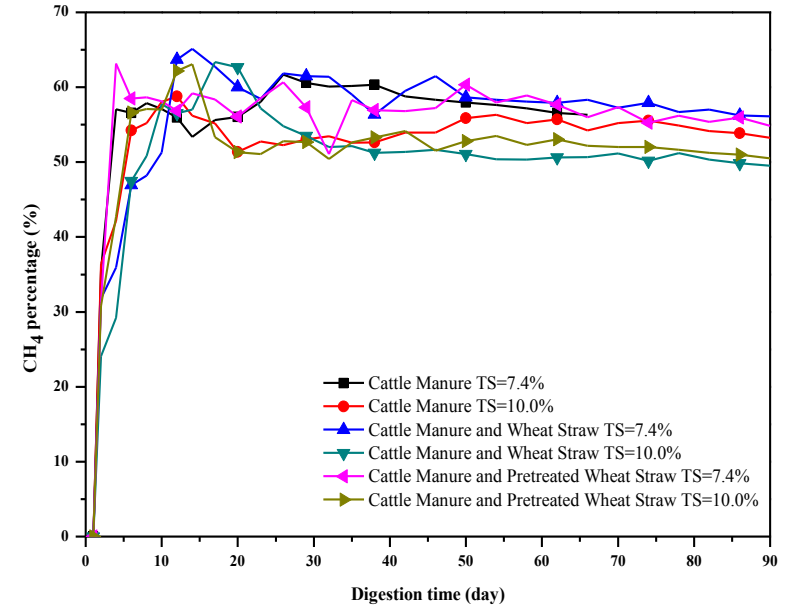

Fig. 4. The cumulative biogas production in different material and total solid.

It can be observed from the $\mathrm{CH}_{4}$ percentage curve line of single cattle manure that the average percentage of $\mathrm{CH}_{4}$ is $56.53 \%$ at $\mathrm{TS}=7.4 \%$, the average percentage of $\mathrm{CH}_{4}$ is $58.89 \%$ at $\mathrm{TS}=10.0 \%$. As shown in Fig. 4 , at $\mathrm{TS}=10.0 \%$, the percentage of $\mathrm{CH}_{4}$ is lower than that at $\mathrm{TS}=7.4 \%$ for most of time during the whole reaction cycle. In addition, the $\mathrm{CH}_{4}$ percentage curve line of every groups show a similar conclusion, that the percentage of $\mathrm{CH}_{4}$ at $\mathrm{TS}=10.0 \%$ is always lower than that at $\mathrm{TS}=7.4 \%$ after the early stage of reaction.

The main reason for this situation is that, in the early stage of reaction, the content of organic matter in the raw materials is more abundant and non-methanogens bacteria metabolize quickly and generates a large amount of acetic acid and $\mathrm{CO}_{2}$. Then part of the $\mathrm{CO}_{2}$ dissolves in the feed liquid and reduces the $\mathrm{PH}$, which inhibits the methanogenic activity, and the percentage of $\mathrm{CH}_{4}$ is low. In the middle and later stages of the reaction, the content of organic matter is sufficient, and the rate of non-methanogens bacterium degradation is faster than methanogens. More $\mathrm{CO}_{2}$ surplus is overflowed with biogas, and the percentage of methane at $\mathrm{TS}=10.0 \%$ is lower than that at $\mathrm{TS}=7.4 \%$.

\subsection{Analysis of anaerobic digestion time and biogas production rate}

\subsubsection{Analysis of anaerobic digestion time}




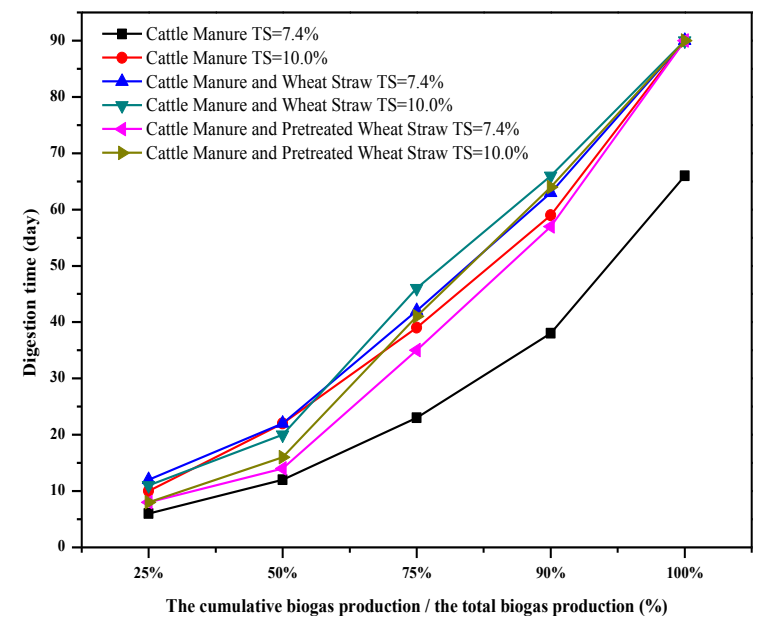

Fig. 5. Hydraulic retention time of anaerobic fermentation. Fig. 5 shows that the times to reach $25 \%, 50 \%, 75 \%$ and $90 \%$ of the total biogas production are various. The group of single cattle manure is the shortest, the group of cattle manure and pretreated wheat straw is the next, and the cattle manure and wheat straw are the longest at $\mathrm{TS}=7.4 \%$. It also shows that the time is prolonged by adding wheat straw into the cattle manure for anaerobic fermentation cause. Moreover, when wheat straw is pretreated, the time is less, indicating that the pretreatment process has shortened the biogas production cycle. Except the cases of single cattle manure at $\mathrm{TS}=7.4 \%$, it takes 56-66 days for the cumulative biogas production to amount to $90 \%$ of the total biogas production, and 90 days to amount to $100 \%$ of the total production. Therefore, it is most efficient to stop the anaerobic fermentation process after 60 days from the beginning. This will not only significantly shorten the gas cycle, but also ensure that the raw materials are fully utilized.

\subsubsection{Analysis of anaerobic digestion time}

During anaerobic digestion process, methanogens and non-methanogens bacteria can only decompose to volatile solids content (VS) in the feed while ash cannot be degraded. Therefore, TS or VS biogas production rates can be used to determine the level of raw material utilization.

Table 3. The biogas production rate of TS and VS.

\begin{tabular}{|c|c|c|c|c|c|c|}
\hline Nature & $\begin{array}{c}\text { Group } \\
\text { I }\end{array}$ & $\begin{array}{c}\text { Group } \\
\text { II }\end{array}$ & $\begin{array}{c}\text { Group } \\
\text { III }\end{array}$ & $\begin{array}{c}\text { Group } \\
\text { IV }\end{array}$ & $\begin{array}{c}\text { Group } \\
\text { V }\end{array}$ & $\begin{array}{c}\text { Group } \\
\text { VI }\end{array}$ \\
\hline TS $=$ & $7.4 \%$ & $7.4 \%$ & $7.4 \%$ & $10.0 \%$ & $10.0 \%$ & $10.0 \%$ \\
\hline $\begin{array}{c}\text { Cumulative } \\
\text { biogas } \\
\text { production in } \\
\text { the first 30 } \\
\left.\text { days(m }{ }^{3}\right)\end{array}$ & 0.954 & 1.218 & 1.322 & 0.847 & 1.707 & 1.805 \\
\hline $\begin{array}{c}\text { Total biogas } \\
\left.\text { production(m }{ }^{3}\right)\end{array}$ & 1.138 & 1.946 & 1.854 & 1.320 & 2.822 & 2.685 \\
\hline TS(kg) & 6.609 & 7.145 & 7.145 & 8.564 & 9.501 & 9.501 \\
\hline VS(TS) & 4.878 & 5.361 & 5.361 & 7.665 & 8.478 & 8.478 \\
\hline $\begin{array}{c}\text { The relative } \\
\text { percentage of } \\
\text { the first 30 } \\
\text { days (\%) }\end{array}$ & 83.9 & 62.6 & 71.3 & 64.1 & 60.5 & 67.2 \\
\hline $\begin{array}{c}\text { TS biogas } \\
\text { production } \\
\left.\text { rate(m }{ }^{3} / \mathrm{kgTS}\right)\end{array}$ & 0.188 & 0.272 & 0.259 & 0.154 & 0.297 & 0.283 \\
\hline $\begin{array}{c}\text { VS biogas } \\
\text { production }\end{array}$ & 0.233 & 0.363 & 0.346 & 0.172 & 0.333 & 0.317 \\
\hline
\end{tabular}
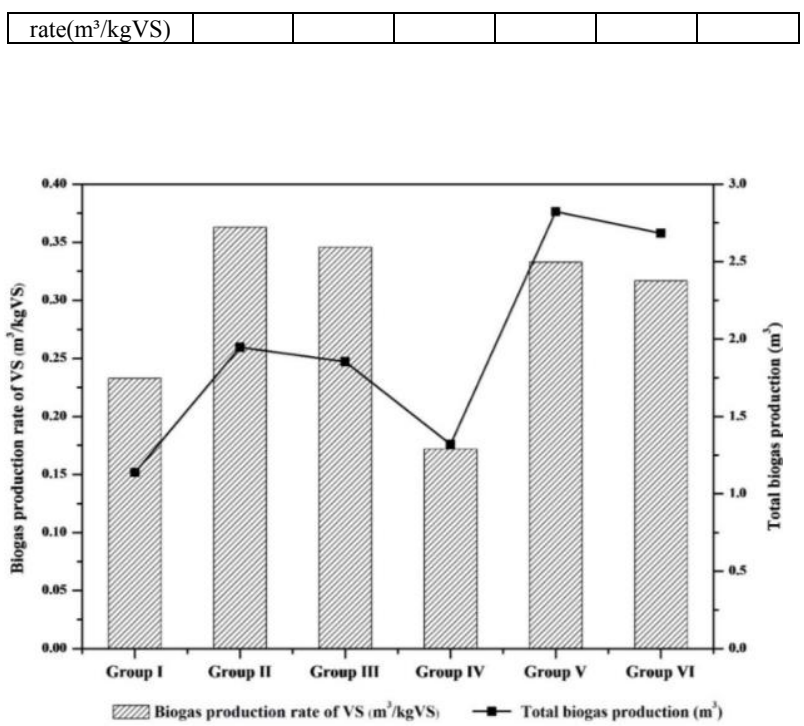

Fig. 6. The biogas production rate histogram of each group. It can be seen from Table 3 that with the same raw materials, the utilization of raw materials at $\mathrm{TS}=7.4 \%$ is lower than that at $\mathrm{TS}=10.0 \%$ from biogas production rate of TS. However, the utilization of raw materials gets opposite results from biogas production rate of VS, because there is not volatile gravel in the cattle manure, so the biogas production rate of VS is used to reflect the level of raw material utilization in this paper. As shown in Fig. 6 and Table 3, the production rate ranking of the raw material biogas is Group I $>$ Group IV $>$ Group II $>$ Group V $>$ Group III $>$ Group VI. The comparison of biogas yield is Group IV $>$ Group I, Group V $>$ Group II, Group VI $>$ Group III. It is pointed out that under the same raw material and pretreatment conditions, when TS increases from $7.4 \%$ to $10.0 \%$, biogas yield increases and the raw material utilization decreases.

\section{Conclusions}

1) In the same fermentation liquid, the total biogas yield increases with the growth of TS content, and the maximum cumulative biogas production occurs at $\mathrm{TS}=10.0 \%$ when cattle manure and wheat straw are used as the raw material.

2) The anaerobic fermentation of each group mainly occurs on the first 30 days. According to the ratio of the accumulated biogas production to the total biogas production in the first 30 days, it can be concluded that the utilization of the organic matter in the raw materials reduces with the increase of the total solid content. The optimal feeding utilization rate is found at $\mathrm{TS}=7.4 \%$ when cattle manure and pretreated wheat straw are used as the raw material.

3) Under the same conditions, when the TS increases from $7.4 \%$ to $10.0 \%$, the anaerobic fermentation cycle is prolonged and the total biogas production increases, but the utilization rate of raw materials decreases and the environment of anaerobic fermentation microbial metabolic activity is more easily formed. In practical engineering, the fermentation cycle and the effect of total biogas production should be taken into consideration. In addition, the optimal total solid content 
for different fermentation raw materials should also be determined to achieve the most efficient fermentation of biogas.

\section{References}

1. Zhang Dong, et al. Treatment Technology of Livestock Manure Biogas Project. Journal of Zhejiang agricultural sciences, 2(2012): 223-227

2. Zhang Wudi, Song Hongchuan, Li Jianchang, et al. Rural Energy for Sustainable Development of Agriculture; Biomass Energy. Agriculture and Technology, 21(2001): 8-12

3. Li Jingming. Future: The Development of Biogas Industry in China. China International Biomass Energy and Biomass Utilization Summit, (2014)

4. Liu Ronghou, Hao Yuanyuan, Ye Ziliang, et al. Experimental Study on the Effect of Biogas Fermentation Process Parameters on Biogas and Biogas Slurry Composition. Journal of Agricultural Engineering, 22(2006): 85-88

5. C NMulligan. An evaluation of the sustainability of the anaerobic digestion of manure. Proceedings 10th World Congress AD, Montreal, Canada, (2004) 1786-17891.

6. Teodorita Al Seadi, et al. Good Practice in Quality Management of AD Residue.

7. Gorisch U, Helm M. Biogas plants. Stuttgart, Germany: Ulmer, (2006)

8. Lin Cong, Duan Na, Wang Yang, Zhang Youhong. Development Status and Thinking of Biogas Engineering in Germany. Swine Industry Science, 7(2009)

9. Shou Yifeng. Development Status and Trend of Biogas Industry in USA. Scientific Research.

10. Tian Ying. Energy Sustainable Development Strategy in Sweden. http: //www. Isase /templates /News_50822. aspx. (2006)

11. LantzM, Svensson M, Bjrnsson L, Brjesson P. The Prospects for an Expansion of Biogas Systems in Sweden - Incentives, Barriers and Potentials. Energy Policy, 35 (2007): 1830 -1843. 